\title{
Para repensar a região: uma proposta de ensino integrado de Geografia e História
}

Jocelito Zalla*

Maira Suertegaray Rossato ${ }^{* *}$

Resumo: Frente à atualidade do debate sobre identidades nacionais e regionais, propomos, neste trabalho, a análise de uma ação de ensino integrada de Geografia e História, realizada no CAp-UFRGS, que pretendeu traduzir em novas estratégias e abordagens didáticas os conhecimentos acadêmicos sobre a construção da ideia de região e da figura do gaúcho tradicional no Rio Grande do Sul. Para tanto, também tecemos um breve balanço do desenvolvimento teórico do conceito de região nos meios especializados e um rápido histórico da produção do mito do gaúcho pampiano no estado. Os resultados da ação mostram ser possível utilizar a temática para construir, com os estudantes, conceitos interdisciplinares (como fronteira, nação, região, estereótipo), desnaturalizando na sala de aula uma identidade que se apresenta como fixa e essencialista e fomentando a tolerância e o respeito à diversidade cultural.

Palavras-chave: Região; Identidade; Educação; Geografia; História.

* Mestre em História pela Universidade Federal do Rio Grande do Sul. Docente do Departamento de Humanidades do Colégio de Aplicação-UFRGS, professor de História do Projeto Amora. E-mail: zallaj@hotmail.com.

* Doutora em Geografia pela Universidade Federal do Rio Grande do Sul. Docente do Departamento de Humanidades do Colégio de Aplicação-UFRGS, professora de Geografia do Projeto Amora. E-mail: mairasuerte@gmail.com. 


\begin{abstract}
Faced with today's debate about national and regional identities, we propose, in this work, the analysis of an integrated education action of Geography and History, held at CAp-UFRGS, which intended to translate into new strategies and didactic approaches the academic knowledge about the construction of the idea of the region and the figure of the Gaucho in Rio Grande do Sul. To this end, we also weaved a brief balance of the theoretical development of the concept of region in the specialized studies and a quick history of the production of the myth of the Gaucho "pampiano" in the state. The action results show it is possible to use the theme to build with students interdisciplinary concepts (such as frontier, nation, region, stereotype), denaturalizing, in the classroom, an identity that is presented as fixed and essentialist and encouraging tolerance and respect for cultural diversity.
\end{abstract}

Keywords: Region; Identity; Education; Geography; History.

\title{
Introdução
}

A região é uma dimensão fundamental da vida social, somente ultrapassada pela nação como unidade de referência identitária no final do século XIX e início do século XX. ${ }^{1}$ Mas os mesmos processos sócio-históricos que levaram à expansão dos projetos nacionalistas, como a organização e centralização administrativa dos estados, a soberania política do povo e a disseminação da economia capitalista de mercado, têm produzido movimentos de resistência cultural em níveis locais, apelando a antigos mitos e costumes e inventando tradições altamente formalizadas. Tudo se passa como se o avanço de padrões convergentes de organização, produção e consumo de bens materiais e simbólicos fomentasse um sentimento generalizado de perda

\footnotetext{
Para um histórico da escala como unidade social, sua substituição/convivência com a "nação" e possíveis implicações pedagógicas do processo no ensino de História, ver Marcos Lobato Martins, 2010.
} 
de raízes e, corolariamente, a afirmação das especificidades. Nesse contexto, há, de um lado, demandas crescentes pelo domínio e pela compreensão da realidade regional e, de outro, vindo ao seu encontro, discursos regionalistas, nos âmbitos da cultura e da política, que operam com estereótipos sobre os habitantes da comunidade imaginada local e, para estabelecer seus limites simbólicos, propagam preconceitos sobre esses e seus "outros".

O fenômeno é bastante conhecido e foi amplamente documentado pela bibliografia acadêmica, em áreas como História, Antropologia, Estudos Literários e Geografia. Para ficarmos em um exemplo, vale lembrar que o crítico argentino Ángel Rama (2001) apontava que a literatura regionalista na América Latina deveria ser compreendida como resposta à penetração da modernidade em zonas afastadas, imobilizadas ou em decadência, após surtos de desenvolvimento econômico. Em um país de proporções continentais como o nosso, em que a incorporação dos "sertôes" ao modelo civilizacional difundido pelo "moderno" litoral teve lento (e violento) percurso, a análise revela-se muito pertinente. No século das nações, o Brasil só podia se imaginar uno apelando às peculiares características locais, daí sua ainda hoje comum representação como grande mosaico cultural. Isso também explica o fato de que o regionalismo literário romântico não vingou somente na pena de escritores como José de Alencar, que falavam ao público do centro do Império, interessado nas especificidades dos demais brasileiros, mas serviu de modelo ao estabelecimento das letras locais em diversos pontos do país. Dessa forma, criavam-se imagens extremamente plásticas sobre o sertanejo, o gaúcho, o caipira paulista e, mais recentemente, o nordestino. Todas pautadas pela visão que os homens da cidade tinham dos "caboclos" e campesinos e dessa maneira reproduzidas em larga escala, não só pela literatura de ficção, mas através do jornalismo político, do folclore, da historiografia tradicional e, nas últimas décadas, da filmografia e produção televisiva. $\mathrm{O}$ caso do Rio Grande do Sul, como veremos a seguir, é, no mínimo, emblemático, pelo que há nele de geral, mas também pelo 
desproporcional peso e legitimidade da questão regional em sua história recente.

É importante ressaltar que esses esforços de interpretação acadêmica do regionalismo brasileiro, além da própria categoria de "região", ainda encontram pouca correspondência nos currículos escolares e na prática docente no Ensino Básico. Outrossim, não é incomum verificarmos que a escola, quando propõe-se a discutir a questão, pode assumir o ponto de vista dos movimentos folclóricos e reforçar a retórica da perda e da salvaguarda das tradiçóes populares. Nesse caso, o argumento, muitas vezes, é tautológico: "A tradição corre perigo de extinção; há-se, portanto, que preservá-la, pois é tradição". Pouco reflete-se sobre sua natureza, movimento que revelaria o quanto há nela de invenção recente, operada por intelectuais especializados, com propósitos políticos nem sempre nobres. ${ }^{2}$

Como fugir dessa armadilha e traduzir os avanços analíticos das Ciências Sociais sobre o tema em novas estratégias e abordagens didáticas? A resposta não é fácil e, em larga escala, provavelmente esbarraria em certas resistências de parcela da sociedade e do Estado. Mas parece que é tempo de ensaiar algumas tentativas. E, para isso, já há bastante suporte legal e pedagógico.

Atualmente, é amplo o debate acerca da necessidade de desconstruir estereótipos e reducionismos, a partir do respeito às diferenças, do reconhecimento da complexidade sociocultural e da multiculturalidade. Tal discussão ganhou força a partir da inserção de novas leis e diretrizes que demandam práticas pedagógicas que viabilizem a convivência democrática entre diferentes grupos e culturas, como o Referencial Curricular Nacional para as Escolas Indígenas, as políticas afirmativas das minorias étnicas, as propostas de inclusão de pessoas portadoras de necessidades especiais na escola regular, a ampliação e o reconhecimento dos movimentos de gênero, entre outros. Vale lembrar que um dos

2 Para uma discussão teórica sobre o tema, ver o clássico estudo introdutório de Eric Hobsbawm ao livro $A$ invenção das tradições (2002), por ele organizado em conjunto com Terence Ranger. 
temas transversais recomendados pelos Planos Curriculares Nacionais (PCNs) é o da "pluralidade cultural".

Neste artigo, queremos compartilhar uma experiência de ensino, desenvolvida no Projeto Amora do Colégio de Aplicação da UFRGS, que buscou soluções aos problemas enunciados anteriormente, indo ao encontro das políticas de valorização da diversidade. Trata-se da oficina Geografia imaginária do Rio Grande do Sul, por nós ministrada no primeiro semestre de 2011, com um grupo misto de alunos de quinta e sexta séries do Ensino Fundamental. Com isso, objetiva-se analisar os resultados da ação e discutir a possibilidade de extrapolá-la e/ou adaptá-la a outros contextos escolares. Antes, trazemos um breve balanço do desenvolvimento teórico do conceito de região nos meios especializados e, para que o leitor reconheça a realidade que foi tratada na sala de aula, teceremos ainda um rápido histórico da produção do mito do gaúcho e da ideia de Rio Grande do Sul que nele se assenta.

\section{Sobre os conceitos de região e de regionalismo}

O conceito de região assumiu e ainda assume diferentes significados. Sua trajetória caracteriza-se pela polissemia, devido à sua ampla utilização nos mais variados discursos, desde os acadêmicos até aqueles do senso comum.

Contudo, enquanto importante categoria trabalhada pela Geografia, pode-se sintetizar o conceito de região em duas ideias distintas: ela existe na realidade, enquanto objeto (espaço absoluto), ou ela existe na mente do pesquisador (espaço relativo) e deve ser definida por ele através de critérios preestabelecidos, configurando-se como resultado de um método.

$\mathrm{O}$ conceito de região enquanto espaço absoluto foi bastante difundido no século XIX e, nessa visão, as regiões existiam a priori. Elas consistiam num entorno vivencial instalado na percepção 
dos habitantes e, nesse caso, os geógrafos deveriam descobri-la. Assim, depois de identificados/definidos seus limites, a região era estudada em detalhe, considerando a totalidade de seus aspectos físicos e humanos, chegando a grandes inventários que compunham as chamadas monografias geográficas regionais, que tiveram grande representatividade dada pela Geografia francesa de Paul Vidal de La Blache. Esses trabalhos consideravam a região como um objeto de estudo e privilegiavam os aspectos físicos como suporte das atividades humanas (BUZAI, 2004).

A região que existe na mente (espaço relativo), enquanto artifício ou enquanto resultado de método (GRIGG, 1974), surgiu na década de 20, com os trabalhos do geógrafo alemão Alfred Hettner, sendo amplamente difundida, mais tarde, por Richard Hartshorne, em 1939. Esses trabalhos pautavam-se pelo reconhecimento de que as regiões eram fragmentos de terra, cujos limites eram definidos com uso de critérios arbitrários, eram recortes feitos pelo exercício intelectual, não existindo em si mesmas, enquanto objetos concretos.

Para Hettner, a análise regional leva em consideração um conjunto heterogêneo de fenômenos que possuam coerência interna própria, conformando uma individualidade referida no tempo e no espaço (LENCIONI, 1999). A determinação dos fenômenos a serem analisados é tarefa do pesquisador, considerando seus objetivos de estudo. O método regional estaria, então, determinado por procedimentos intelectuais precisos para a construção de áreas e, na Geografia, este está fundamentado na análise espacial de associações do ponto de vista qualitativo (BUZAI, 2004).

Com a crítica ao quantitativismo, os limites postos no espaço mudam de rumo, já que os estudos geográficos mudam seu foco de interesse. Na década de 70, despontam na Geografia duas posturas diferenciadas que se opunham radicalmente ao quantitativismo: a Geografia Humanista, baseada nos estudos da percepção e da valorização do mundo vivido e a Geografia Crítica ou Marxista, baseada na teoria marxista que considerava o espaço geográfico como resultado das relaçôes capitalistas de produção em macroescala. 
Segundo Suertegaray $(2005$, p. 55),

A Geografia Marxista vai reavaliar o conceito e vai pensar e analisar o espaço geográfico a partir de uma concepção de região que se define a partir de um contexto histórico e o associa a divisão territorial do trabalho. Região é, portanto, uma construção de espaço vinculado à divisão territorial do trabalho que advém da forma como, na contemporaneidade, sob a lógica do Modo de Produção Capitalista, se organiza o processo produtivo.

Mas para além da dimensão político-econômica de análise da região, pode-se incorporar a dimensão simbólico-cultural, como destaca Haesbaert (1988) em seu estudo sobre a campanha gaúcha, no qual aborda a região a partir dos regionalismos e da identidade regional, conformadores de um bloco regional de uma fração regionalmente hegemônica da classe dominante. Para Haesbaert (2010, p. 53),

Neste caso, o reconhecimento da região - ou da 'condição regional' - não se dá como um simples artifício metodológico criado pelo pesquisador, mas efetivamente se reconhece sua construção a partir de práticas sociais específicas - no caso, a identidade cultural e uma certa representatividade política (na defesa de interesses - notadamente econômicos - vinculados ao espaço regional).

Nesse sentido, a região pode ser, também, compreendida como espaço identitário para um determinado grupo social, que se consolida nos regionalismos e que se expressa pelo hibridismo do político, do econômico e do cultural, enquanto construção de representações que fortaleçam a identidade (SUERTEGARAY, 2005). E é através desse viés que enfocamos o trabalho realizado com a oficina Geografia Imaginária do Rio Grande do Sul.

A região é concebida a partir do "[...] processo de invenção discursiva, aliando conceito e metáfora, ciência e arte" (THRIFT apud HAESBAERT, 2010, p. 67). Ela emerge das nossas geografias imaginárias, as quais utilizamos para reconstruir constantemente nossas referências identitárias. Albuquerque Júnior (1999 apud HAESBAERT, 2010, p. 69) destaca, a exemplo da construção do Nordeste, que "[...] a região se institui, paulatinamente, por meio de práticas e discursos, imagens e textos que podem ter, ou não, 
relação entre si, um não representa o outro. A verdade sobre a região é constituída a partir desta batalha entre o visível e o dizível". Assim como inventa-se a região, inventam-se os sujeitos regionais (nordestino, gaúcho, caipira), sujeitos esses produzidos também a partir das práticas espaciais percebidas e de um espaço representado ou vivido.

Outro ponto de destaque é que esta região amparada no discurso regionalista é instituída e sustentada a partir de redes de poder que se estabelecem espacialmente, estando também apoiada na produção de uma sensibilidade regionalista, isto é, uma cultura na qual práticas regionalistas são incorporadas por várias camadas da população e surgem como elementos dos discursos desses vários segmentos (ALBUQUERQUE JÚNIOR apud HAESBAERT, 2010).

Mesmo sendo essa uma abordagem mais recente na Geografia, a construção ou a invenção das regiões (na prática) a partir das identidades regionais não é nova.

\section{A produção do estereótipo: o caso do Rio Grande do Sul}

A crítica especializada, nas mais diversas áreas ${ }^{3}$, revela que a criação do mito do gaúcho, cavaleiro errante romantizado, só foi possível após sua morte como tipo social. Foi na segunda metade do século XIX, quando formas de organização capitalista chegavam ao campo no Rio Grande e nos países vizinhos, erradicando maneiras tradicionais de vida, que o gaúcho começou a ser desenhado como marco da identidade regional. Enquanto o antigo andarilho passava a ser confundido com o novo peão de

3 É interessante notar como a identificação da morte ou decadência do gaúcho rural e sua relação com a produção de uma vasta literatura gauchesca no Estado (e nos países platinos) une trabalhos e pesquisas com variado leque de preocupaçóes e abordagens, em períodos também distintos, englobando diferentes geraçốes de intelectuais. 
estância ${ }^{4}$, a desmobilização da sociedade sul-rio-grandense para a guerra permitia, nas maiores cidades, os primeiros esforços intelectuais consideráveis, como a criação de periódicos e academias literárias. Desde logo, os novos escritores da província debruçaram-se sobre a figura, antevista nas crônicas de viajantes que por aqui passaram, dando-lhe cores mais vivas e condizentes com o projeto romântico de criação da nação.

A escolha do gaúcho como tipo folclórico representativo da região não foi pacífica, gerando sérias implicâncias ao longo de todo o processo de consolidação e atualização do mito. Visto no século anterior como bandido social, ele causava suspeitas não somente no centro do país, mas também entre a população urbana local. ${ }^{5}$ Como mostrado por Carla Renata Gomes (2009), o gaúcho foi inicialmente o antípoda do sul-rio-grandense. Mas, dadas as mudanças sociais já citadas e o investimento simbólico efetivado pelos intelectuais, aos poucos, também o termogaúcho passou por um processo de positivação, o que permitiu, no século $\mathrm{XX}$, sua adoção definitiva como adjetivo gentílico.

Ainda hoje, o debate identitário no estado é pautado mais pelo mito, quer dizer, pela visão idealizada dogaúcho, do que pela figura histórica que o inspira. Pode-se dizer que herdamos do regionalismo romântico um arquétipo bastante forte e difícil de contornar. Quais são, então, suas formas e seus conteúdos mais usuais? Grosso modo, ele é caracterizado como cavaleiro que goza de grande liberdade de ir e vir, percorrendo longas distâncias pelas coxilhas sulinas, deserto verde sem cercas e limites precisos, no trato com o gado. A faina campeira confere-lhe atributos quase sobre-humanos, como força, bravura e coragem extremadas. Daí sua predisposição à guerra: peão habilidoso com os instrumentos de carneação, também o é com as armas brancas. Mas é nobre,

4 Esse processo foi identificado e analisado pioneiramente pelo crítico Augusto Meyer (1957), cuja interpretação foi validada pela historiografia profissional recente.

5 Segundo César Guazzeli (2002), além dos delitos associados à figura, seu aliciamento em hostes irregulares dos caudilhos nas guerras de independência e nas disputas que se seguiram ao processo de formação dos Estados nacionais na região platina o manteve como legenda negra por boa parte do século XIX. 
acima de tudo. Segue rigorosa moral forjada na vida da fronteira: é leal aos chefes e aos companheiros, preferindo a morte à desonra. Também é hospitaleiro, recebendo bem sem olhar a quem; sempre há espaço para o repouso do viajante no galpão da estância, com fogo de chão e chimarrão para afugentar o frio. Churrasco é sua comida diária, e o apreço pela carne é distintivo. Pese certa misoginia, conferida pela pouca convivência com as mulheres na estância, o gaúcho de verdade é sempre respeitoso para com elas. Por último, sua bravura não é sinônimo de algazarra. Além de trabalhador, é ordeiro.

Dessa maneira compreendido, o gaúcho torna-se praticamente um herói sem nome, pois representa uma coletividade que, mesmo excedendo sua realidade primária, compartilharia com ele um jeito de ser. Indo além dessa casta social imaginária, o ethos gaudério seria reconhecível em todo habitante do estado.

Com tal configuração, fica fácil compreender a ideia de região ligada à figura: é um mundo rural por excelência, inclinado, principalmente, à pecuária extensiva, cujas formas tradicionais exigem latifúndios, com livre trânsito de homens, seus bois e cavalos. A paisagem imaginada é sempre o Pampa, termo de origem indígena para região plana. Esta paisagem caracteriza-se pelo relevo aplainado com suaves ondulaçôes chamadas coxilhas. A vegetação é basicamente campestre. Plantas herbáceas e arbustivas são dominantes, enquanto que as formações florestais restringem-se principalmente às margens dos rios. A paisagem do que, atualmente, chama-se bioma Pampa é encontrada ao sul do Estado do Rio Grande do Sul, atingindo o Uruguai e a Argentina. A continuidade geográfica explica as fáceis trocas econômicas e as indesejáveis proximidades culturais com os países platinos. Todavia (e este é um adendo criado pela historiografia tradicional do século XX), como fronteira, é terra de um povo que luta para garantir a brasilidade no sul do continente, pegando em armas sempre que seja necessário defender o país. Distante de seu centro administrativo e político, a região vive ainda em relativa autonomia e, como ressaltaram os olhares românticos 
oitocentistas, isenta dos vícios civilizacionais com os quais padecia o Rio de Janeiro, sucedâneo americano do velho mundo.

Ao longo do tempo, tais imagens foram insistentemente reproduzidas e atualizadas em discursos literários e políticos locais. No campo da ficção, o gênero gauchesco criou profundas raízes na escrita local, afirmando-se como dominante por boa parte do século passado, apesar das mais variadas vertentes, inclusive antagônicas, que nele beberam. ${ }^{6}$

A partir da década de 1920, com a fundação do Instituto Histórico e Geográfico do Rio Grande do Sul (IGHRS), uma nova geração de historiadores criou e oficializou uma perspectiva de memória pública tributária do mito literário do gaúcho, despindo-o, no entanto, das inconvenientes suspeitas de barbárie e banditismo, além de hispanismos culturais pouco tolerados a um país que, mais uma vez, buscava a unificação nacional.

Com a repressão do Estado Novo (1937-1945), ironicamente comandado pelo gaúcho Getúlio Vargas, aos particularismos políticos e culturais, o mito enfraqueceu-se, sumindo da cena pública. Mas, ao que tudo indica, não do imaginário popular. Daí a grande receptividade que, findo o regime getulista ${ }^{7}$, ganhou o gaúcho redesenhado pela Comissão Estadual de Folclore e pelo nascente movimento tradicionalista. Quando jovens estudantes do Colégio Júlio de Castilhos, capitaneados pelos colegas João Carlos D’Ávila Paixão Côrtes e Luiz Carlos Barbosa Lessa, fundaram as primeiras entidades tradicionalistas ${ }^{8}$, o gauchismo cívico por eles inventado se inspirava em representações sociais de

6 Do regionalismo naturalista ao realismo denunciatório, da celebração ufanista à crítica "disfórica", para usar os termos do escritor Cyro Martins (1979), quer dizer, da exaltação do arquétipo, criado no século anterior, à sua desmistificação.

7 Nessa momento, o regional, categoria combatida pelo centralismo político e pela perspectiva de "popular-nacional" buscada pelos intelectuais do Estado Novo (VELLOSO, 2003), retornava ao debate público nos Estados periféricos, sendo disputado, reconfigurado e divulgado pelos novos meios de comunicação de massa, como o rádio e o cinema (OLIVEIRA, 2003).

8 Em 1948, foi criado o Departamento de Tradições Gaúchas do Colégio. No ano seguinte, o 35' Centro de Tradições Gaúchas, modelo dos novos CTGs que se proliferaram pelo estado e para além dele na segunda metade do século XX. 
longa duração, incluindo as imagens literárias e historiográficas construídas pela erudição local.

A difusão da perspectiva tradicionalista deu-se principalmente pela elaboração de ritos de fácil reprodução, como danças de inspiração folclórica, uma sociabilidade inspirada na hierarquia idealizada da estância, dividida entre patrão e peões e, inclusive, a invenção de um modelo de ser mulher, a "prenda", cujo traje, um longo vestido rendado, sequer tinha fundamento histórico, já que nunca fora utilizado pelas "gaúchas" de outrora (ZALLA, 2010). ${ }^{9}$

$\mathrm{O}$ mesmo grupo deu início à dinâmica que viríamos a chamar de Semana Farroupilha. Denominada inicialmente de Ronda Gauicha e, a seguir, Ronda Crioula, caracterizou-se pela realização de comemorações em torno de uma centelha retirada da Pira da Pátria, por ocasião dos festejos da independência do Brasil, contando com atividades artísticas, campeiras e debates intelectuais sobre a literatura e a história do Rio Grande do Sul. Ao longo dos anos, o evento constituiu-se em um ritual de alta adesão, ganhando patrocínio do Estado. ${ }^{10} \mathrm{O}$ mito do gaúcho a cavalo encontrou nessa celebração espaço privilegiado para sua afirmação e disseminação, com a evocação periódica de toda a gama de símbolos e "tradiçôes" inventadas por nossos intelectuais desde o século XIX.

9 Para outras análises acadêmicas sobre o movimento tradicionalista, ver Oliven (1992, 2006), Maciel (2000), Nedel (2005).

10 A lei n. 4.850, assinada em 11 de dezembro de 1964 pelo deputado Francisco Solano Borges, então Presidente da Assembleia Legislativa do Estado do Rio Grande do Sul, oficializa a "Semana Farroupilha", "[...] a ser comemorada de 14 a 20 de setembro de cada ano, em homenagem e memória aos heróis farroupilhas”, segundo definição do Art. 1. 


\section{A recepção do mito: as representações dos estudantes sobre a região}

Repensar a região e o regionalismo sul-rio-grandense na sala de aula é, como vimos, um grande desafio. O planejamento inicial da oficina realizada no Projeto Amora levou em consideração a elaboração teórica do tema, como foi anteriormente vislumbrado, mas sem esquecer a contrapartida empírica. Quer dizer, saber que a região é uma construção discursiva estereotipada e politicamente direcionada não significa conhecer a priori todas as possibilidades de representação as quais sujeitos reais lançam mão no seu processo de constituição identitária. Pensando no público-alvo da ação, estudantes das séries finais do Ensino Fundamental, com média etária entre 11 e 12 anos, há que se perguntar ainda de que maneira o modelo hegemônico de identidade gaúcha os interpela. As imagens mais tradicionais ligadas à região já se encontram formadas? De quais símbolos e signos tais estudantes dispõem? Como se deu/dá a elaboração dessas representações até este momento de sua formação?

A avaliação desses problemas nos impôs uma atividade inicial diagnóstica, definida da seguinte forma: apresentamos aos alunos mapas do Rio Grande do Sul contendo apenas os limites políticos do estado e solicitamos que preenchessem o espaço em branco com imagens e palavras que poderiam caracterizar a região. Para tanto, selecionamos um conjunto de revistas de assuntos gerais que contivessem desde fotografias do bioma Pampa e de situações ligadas ao mundo rural, além de comidas e bebidas identificadas pelo senso comum como típicas, até imagens mais frequentes na realidade dos estudantes, próximas do cotidiano urbano vivido em Porto Alegre e região metropolitana. Além de recortes desse material, a serem escolhidos individualmente, os alunos também poderiam desenhar e escrever livremente o que fosse considerado importante para dar conta da tarefa.

Os trabalhos confeccionados nesse dia apresentaram, na sua maioria, a visão estereotipada já mencionada, na qual o Rio 
Grande do Sul é representado pelo homem do campo, vestido com pilcha e montado a cavalo. Um trabalho, contudo (Figura 1), trouxe outros elementos, como a referência à Serra (região nordeste do RS, caracterizada pela imigração italiana e alemã), a festa do peixe no litoral e também a violência característica dos grandes centros urbanos. Os aspectos positivos e negativos do estado aparecem de forma explícita na produção do aluno, que nela escreveu: "Eu acho que as imagens que estão aí é uma parte boa e uma parte do mal do RS (sic)".

Figura 1

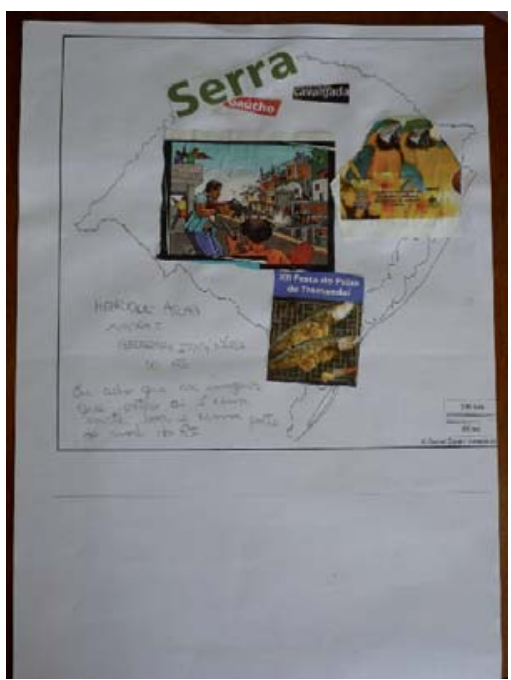

Fonte: Acervo pessoal dos autores

Apesar da (previsível) variação da imagem da região construída pelos estudantes, ficou claro que muitos dos elementos simbólicos erigidos como representativos ao longo da história cultural do Rio Grande do Sul continuam a pautar a visão coletiva sobre o estado. Por sua vez, tal visão já se configura como referencial identitário para a faixa etária considerada. Nesse sentido, optou-se por elaborar as próximas atividades a partir da 
qualificação de conceitos correntes no discurso não especializado, como "região", "nação" e "fronteira".

Na sequência, então, distribuímos novamente mapas em branco, dessa vez do Brasil, com os limites políticos internos definidos. Os estudantes foram provocados a desenhar aspectos que lhes lembrassem de cada estado (Figura 2). O concurso a estereótipos regionais foi a tônica comum. Para os estados amazônicos, por exemplo, surgiram imagens de indígenas e florestas, enquanto que cidades e indústrias marcaram o Estado de São Paulo, e violência, o Estado do Rio de Janeiro. O Rio Grande do Sul foi caracterizado a partir das seguintes imagens: cuias de chimarrão (em todas as produçôes), cavalos e bandeiras do estado, conforme figura abaixo.

Figura 2

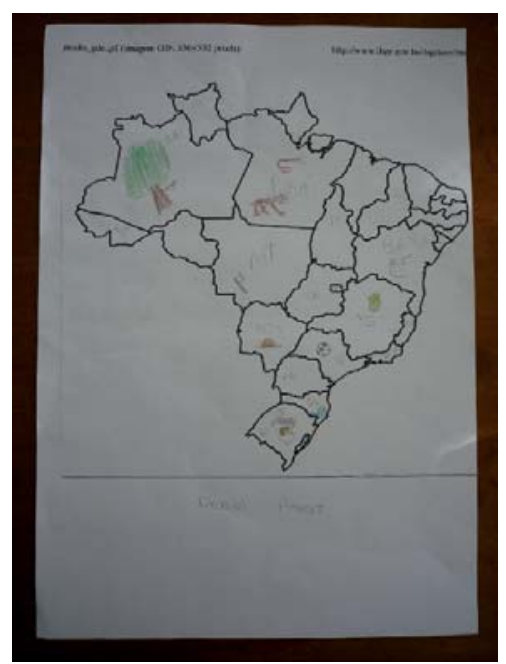

Fonte: Acervo pessoal dos autores

A estratégia escolhida para desconstruir tais estereótipos foi mostrar que as características tomadas como típicas são na verdade produtos de uma seleção; escolhidas pelos agentes 
históricos para criar e/ou reforçar a visão de si almejada. O ciclo de estudos seguinte partiu da necessidade de trabalhar tal questão.

\section{Do geral e do particular: construindo conceitos}

Se o sul do Brasil compartilha elementos culturais com os vizinhos platinos, tais elementos podem, em tese, fundamentar tanto identidades regionais quanto nacionais. Em verdade, o gaúcho histórico foi tomado por movimentos românticos no Uruguai e na Argentina como símbolo da nacionalidade, ainda que não tenha chegado a gozar da mesma hegemonia identificada no Rio Grande do Sul como figura representativa da população local. De caráter marcadamente popular, o gaúcho platino não foi incorporado à história das elites desses países, mas ainda comparece como recurso identitário possível, principalmente quando busca-se ressaltar o aspecto folclórico/folclorista. As noções de região e de nação, portanto, esmaecem-se quando confrontadas com elaborações baseadas em uma cultura fronteiriça.

Para discutir e (re)construir os conceitos de região e nação, assistimos ao filme Alô Amigos, produção de 1943 dos estúdios Disney. No contexto da II Guerra Mundial, havia a necessidade de reforçar os laços políticos entre os países do continente americano, sob a égide dos EUA, potência econômica e militar que despontava como liderança mundial. Os produtores do filme empreenderam uma viagem de campo a alguns países da América Latina, coletando dados para criação de cenas e personagens locais.

$\mathrm{Na}$ atividade de reflexão sobre o vídeo, distribuímos um mapa em branco da América do Sul e pedimos que os estudantes localizassem os países representados, listando palavras-chave de cada lugar. Chamou bastante a atenção dos estudantes o fato de que aspectos culturais e naturais de apenas algumas regiões são promovidos à categoria de nacional, como o samba e a praia 
cariocas para identificar todo o Brasil. Mas impressionados mesmo eles ficaram ao reconhecer na representação da Argentina o gaúcho celebrado recorrentemente no Rio Grande do Sul. Muitos deles afirmaram que a figura encarnada pelo personagem Pateta era igual aos habitantes do nosso Estado. No filme, um Pateta originalmente cowboy é comparado com e transformado em gaucho argentino, paramentado de acordo com as regras estabelecidas pelos grupos folclóricos daquele país. Cenas de apresentações artísticas desses grupos, filmadas durante a excursão dos produtores norte-americanos, são intercaladas ao desenho, afirmando símbolos já bastante conhecidos nos estereótipos da gauchidade fronteiriça: churrasco, mate, bombachas e chiripás masculinos, vestidos compridos para as mulheres, danças de grupo e cantigas de viola.

Com a discussão, pudemos mostrar que os conceitos de região e de nação variam histórica e geograficamente; aspectos culturais ressaltados em determinado espaço que foi construído como região podem ser selecionados para elaborar a ideia de nacionalidade em outros contextos, desde que identificados no passado histórico e/ou imaginado das respectivas populações. Evidentemente, a apropriação e a ressignificação desses elementos compartilhados são determinadas por condições específicas e seus desdobramentos respeitam a história de cada formação política e social.

Ainda neste ciclo, trabalhamos o conceito de estereótipo, a partir das representações das figuras do gaúcho e do brasileiro mostrados no filme Alô amigos. Os estudantes questionaram o porquê do uso de determinadas características para representar o brasileiro, como o samba, as festas, a exuberância da natureza. Partindo dessa problematização, assistimos ao polêmico episódio da série de animação Os Simpsons, no qual a família norte-americana vem de férias para o Brasil e se depara com a criminalidade, animais selvagens em plena cidade e a pobreza disseminada em todos os espaços. Os alunos mostraram-se muito incomodados com a maneira com que o país foi representado no desenho. 
Esse foi o mote para a o debate sobre o termo estereótipo e o que ele representa. A construção de imagens típicas para a nação e a região também revelou-se, assim, uma possibilidade de estereotipia, já que seleciona e ressalta algumas características da realidade, como que em uma caricatura social.

Na sequência, apresentamos duas músicas que descreviam o dia a dia de um gaúcho: Veterano, de Leopoldo Rassier, e Amigo Punk, composta por Frank Jorge e Marcelo Birck. A primeira narra a vida do gaúcho no campo, descreve a sua rotina e o exalta em sua bravura, enquanto a segunda trata de uma realidade urbana, de um gaúcho que gosta de festa e escuta rock pesado. Nossa proposta aqui foi desconstruir o estereótipo do gaúcho tradicional, mostrando que existem outros tipos de "gaúchos": urbanos, que não usam pilcha, não andam a cavalo, podem gostar de carne, mas podem ser vegetarianos. Os alunos, depois da escuta da música, tinham a tarefa de desenhar o gaúcho de cada uma das música a partir dos elementos apresentados na letra. Os resultados foram bastante interessantes: gaúchos tradicionais, ligados ao estereótipo regional, puderam ser comparados a maneiras urbanas, plurais e contemporâneas de se identificar com a identidade local (Figuras 3 e 4 ). 
Figura 3

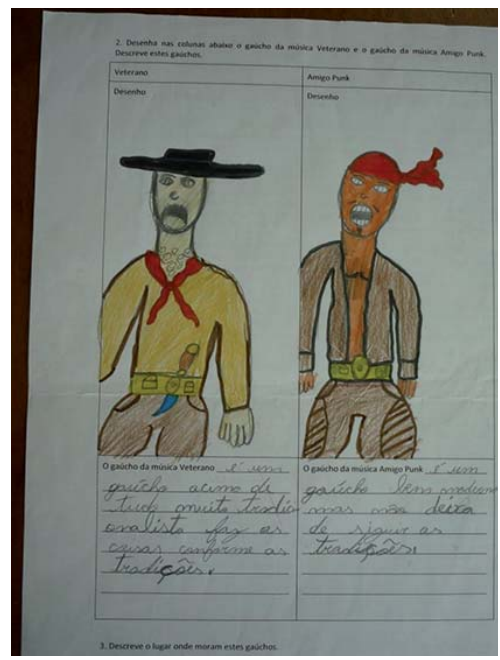

Fonte: Acervo pessoal dos autores

Figura 4

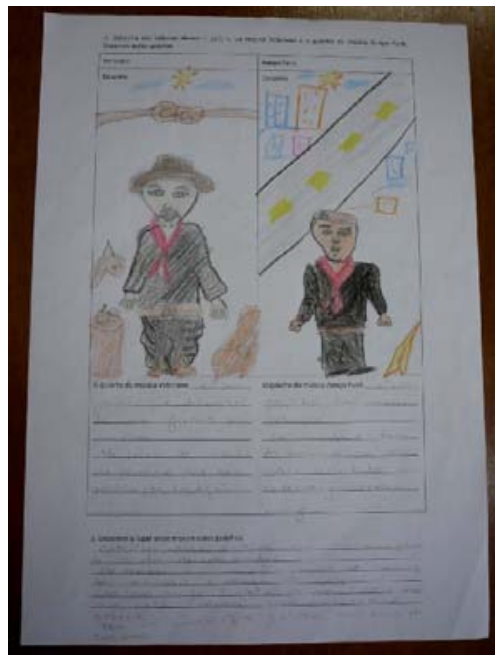

Fonte: Acervo pessoal dos autores 
A distinção entre gaúcho como tipo social histórico e gaúcho como adjetivo gentílico começou, dessa forma, a ser trabalhada, ampliando os significados ligados ao vocábulo, na expectativa de romper com as descrições normativas e restritivas do habitante do Estado no discurso tradicionalista e, como vimos, na memória pública oficial. $\mathrm{Na}$ ocasião dessa discussão, também apresentamos aos alunos alguns dados do IBGE sobre a população do Rio Grande do Sul. Selecionamos aspectos mais marcantes do estereótipo do gaúcho e fizemos um contraponto com dados atuais, mostrando que os gaúchos contemporâneos, pelo menos a maior parte deles, moram nas cidades, trabalham no setor de comércio e serviços, andam de carro, comem carne, mas incluíram na sua alimentação muitos alimentos industrializados. Começou a se delinear então a explicação para a origem do termo gaúcho, trabalhada com profundidade mais adiante.

Como a produção oral e escrita dos estudantes, nesse ciclo, foi marcada pela curiosidade em relação aos países platinos e sobre as trocas ocorridas entre eles e o Rio Grande do Sul ao longo do tempo, o segundo ciclo de estudos foi planejado para explorar o conceito de fronteira e suas potencialidades pedagógicas.

\section{Do imaginado ao real: cultura de fronteira em perspectiva geo-histórica}

Para o entendimento da construção por trás da imagem do gaúcho atualmente difundida, julgamos importante trabalhar os conceitos de limite político e fronteira, muitas vezes concebidos como sinônimos. Limites são linhas demarcatórias que separam dois territórios vizinhos. Podem ser naturais (montanhas, rios etc.) ou artificiais (limites convencionais não definidos por acidentes geográficos). O conceito de fronteira envolve, além da linha do limite, as áreas vizinhas numa largura de $150 \mathrm{~km}$, formando uma faixa ou zona de fronteira. É uma área de superposição e 
justaposição de influências. É um mundo de relações que pode ser ampliado ou fechado através de ações políticas, econômicas, culturais e militares. Pela complexidade das relações que nela se estabelecem, a fronteira possui uma cultura específica. A partir desta diferenciação foi possível trabalhar a definição dos limites do Estado do RS ao longo da história e a caracterização de sua fronteira com os países vizinhos.

$\mathrm{Na}$ fronteira com o Uruguai e a Argentina, percebem-se as influências culturais desses países. A proximidade propicia trocas linguísticas, com vários termos se acastelhanando. Essa situação também ocorre em outros pontos da fronteira, onde a mescla de termos hispânicos e portugueses na linguagem cotidiana é frequente. E, se houve influência na linguagem, também houve no modo de vida (desde características culturais ligadas à arte, à culinária e à vestimenta, bem como às atividades econômicas).

Assim, passamos, na sequência, a confrontar bens culturais produzidos na Argentina e no Brasil, com base no universo gauchesco. A primeira linguagem escolhida foi a canção. Selecionamos uma milonga argentina, Milonga del Peon de Campo, do compositor argentino Atahualpa Yupanqui, e outra brasileira, Meus Amores, do cantor e compositor nativista Luiz Marenco, e comparamos os elementos rítmicos e textuais. Além da temática rural e do gênero musical, chamou muito a atenção dos alunos a existência de vocábulos semelhantes e, mesmo, graficamente idênticos em composições nas línguas espanhola e portuguesa, tais como: poncho, estância, rancho e pago. O levantamento de vocábulos falados na fronteira do RS com influência do espanhol também foi tarefa interessante que mobilizou muito os estudantes. A maioria deles apresentou exemplos trazidos de suas vivências, como pelear, bolicho, sanga, cola, carpetall, entre outros.

11 Pelear - Pelejar, combater, lutar.

Bolicho - Casa de negócio de pequeno sortimento e de pouca importância. Bodega.

Sanga - Pequeno curso d'água menor que um regato ou arroio.

Cola - rabo.

Carpeta - jogo de baralho. 
Selecionamos, então, trechos de textos literários de ambos os países que apresentam temática e forma comum, o gauchesco figurado como contação oral, em que não somente se apela ao vocabulário da cultura representada, mas também a seu modo de narrar. Para explorar mais o contexto platino, assistimos à animação Martín Fierro (2007), baseada no homônimo poema de José Hernández. Como o gaucho argentino é comumente visto como elemento popular, optamos por explorar a história da figura e as variações de sentido em torno do próprio nome gaucho/gaúcho. Através da seleção de trechos de documentos de época (relatos de viajantes, historiografia tradicional e ainda a literatura de imaginação) foi possível conhecer os discursos feitos sobre os gaúchos.

A ideia era problematizar o uso do termo, mostrando que, até meados do século XIX, o vocábulo gaúcho era pejorativo, quer dizer, indicava desaprovação, pois era muito negativo, desagradável e servia para identificar apenas homens errantes, sem trabalho fixo, tidos como vagabundos. Já no final daquele século, passou a ser usado a designar os peões das estâncias ou pequenos proprietários do campo na Argentina. Foi somente no século XX, principalmente na segunda metade, que o termo gaúcho foi adotado como gentílico no Rio Grande do Sul, quando a economia do estado migrava cada vez mais para a indústria e as cidades cresciam aceleradamente. A industrialização e a urbanização, na mesma época, eram apontadas como os principais fatores da extinção do gaúcho tradicional, o que levou à criação, nas cidades, dos Centros de Tradição Gaúcha (CTGs).

\section{"(Des)encontros com o gaúcho": o produto final}

Para avaliar as aprendizagens realizadas, propusemos aos estudantes a elaboração de um vídeo ou de uma fotonovela narrando a história da idealização do gaúcho tradicional. A 
escolha da forma de apresentação da narrativa também foi delegada aos alunos, que optaram por um vídeo, como um filme em curta-metragem. O roteiro foi elaborado em conjunto pelos professores e estudantes. Para tanto, a professora convidada Lisinei Fátima Rodrigues, da área de Teatro do CAp-UFRGS, realizou uma minioficina sobre construção de personagens. Cada estudante criou um perfil, de acordo com as discussões feitas ao longo da oficina. Após apresentar seus personagens aos colegas, o grupo começou a tecer relações possíveis entre eles, dando corpo à narrativa.

Como a preparação do país para a Copa do Mundo de 2014 estava em pauta na mídia no período, os estudantes escolheram como espaço e tempo da história a Porto Alegre durante o mundial de futebol, lançando a hipótese de que nela se encontrarão turistas de vários lugares do mundo, os quais podem se interessar pelo folclore local ou viver situações de estranhamento cultural. Três miniesquetes foram montados, tendo como fio articulador um turista narrador-francês, em telefonema a um amigo em Paris.

Todas as cenas passam-se no Hotel Pampa, que teria como proposta possibilitar aos visitantes uma experiência com a tradição gaúcha. Nele, os funcionários trabalham devidamente pilchados e informam quais os hábitos e costumes do habitante local, segundo o estereótipo regional. No entanto, uma conversa entre os dois recepcionistas revela que ambos têm consciência de que a tradição não representa totalmente a realidade.

O primeiro esquete apresenta um choque entre os gaúchos folclorizados do hotel e três habitantes do campo rio-grandense: um casal de fazendeiros e um peão agregado (Figura 5). Representando o gaúcho do campo real, esses reclamam do caráter fantasioso da caracterização. No segundo esquete, o peão Otacílio, funcionário dos estancieiros, sofre com o preconceito de um turista argentino. Por não acreditar ser apropriado o uso da bombacha na cidade, e partindo de uma experiência diferente com o gauchismo, esse questiona o primeiro. Otacílio defende-se e afirma sua identidade como real, parecendo com isso se distanciar mais uma vez 
dos funcionários do hotel, dizendo ser normal se vestir daquela forma nas terras de onde vem. O último esquete conta uma divertida confusão: tendo ouvido dos recepcionistas que no Rio Grande do Sul se usa a pilcha tradicionalista, um turista coreano compra indumentária completa e passa a vesti-la durante toda a semana, acreditando, assim, estar melhor ambientado. No final, acaba sendo surpreendido por um gaúcho urbano, um skatista que lhe conta a verdade, no que é auxiliado por um policial que tenta acalmar o turista: "é uma homenagem ao gaúcho do campo, mas não se usa todo dia”.

Percebem-se na construção da narrativa, duas preocupações principais: desconstruir o estereótipo regional, mostrando que ele não é representativo do todo, e apontar para a idealização do gaúcho do campo, sem esquecer a tolerância e a diversidade cultural. Criam-se, dessa maneira, várias possibilidades de ser gaúcho gentílico, o que inclui também o gaúcho tradicionalista e o homem do campo, portando bombachas, mas destituído do romantismo folclorista. Um texto simples na forma, encenado dentro dos limites (tecnológicos, teatrais e mesmo cognitivos) disponíveis aos estudantes, mas bastante rico na mensagem principal, evidenciando que os objetivos da oficina foram cumpridos de maneira satisfatória. ${ }^{12}$

12 O vídeo foi postado no site You Tube, sendo encontrado no link: http://www.youtube.com/watch?feature $=$ player_embedded $\& v=$ lpCnRNyOO_k 
Figura 5 - Cena do vídeo (Des)encontros com o gaúcho

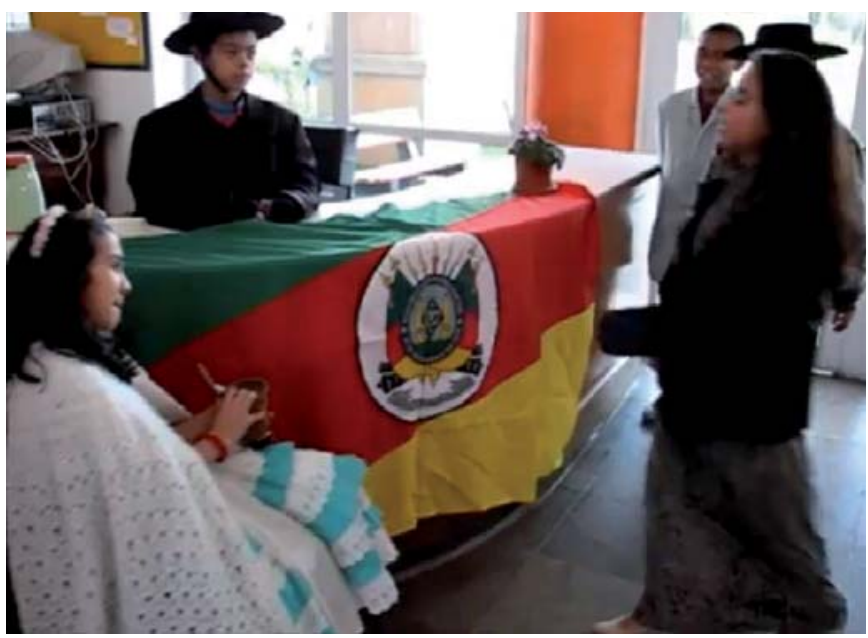

Fonte: Vídeo (Des)encontros com o gaúcho

\section{Considerações finais}

Em estudo já clássico sobre o tratamento do popular pelo erudito, dos folclorismos à produção acadêmica, Jacques Revel, Michel de Certeau e Dominique Julia (1989) refletem sobre a pergunta feita por Morvan Lebesque: "Será possível ser-se bretão?”. A resposta é uma negativa peremptória, a não ser enquanto "objeto abolido e nostálgico". Uma analogia com o processo de construção do gaúcho folclorizado e da ideia de região no Rio Grande do Sul pode ser bem-vinda para concluirmos nossa análise.

Como vimos anteriormente, foi a morte ou a transformação do gaúcho histórico que permitiu sua eleição como símbolo regional, tornando-o objeto de um processo de estetização de longo prazo. A nostalgia configura, assim, uma marca do gauchesco literário e cívico: o saudosismo do passado o torna presente na experiência de leitura ou nos ritos tradicionalistas. Esse viver do que já não é (ou do que nunca foi) não impede, como 
sabemos, a identificação de milhares, se não milhões, de pessoas com modelos de se portar e se relacionar em sociedade criados a partir do passado imaginário do campo gaúcho. Ao confundir-se o folclórico com o gentílico, tais modelos amarram-se discursivamente a caracterizações arbitrárias do povo rio-grandense, naturalizando-se como verdades históricas e culturais frente aos olhos do senso comum.

O que pretendemos, com a ação de ensino-aprendizagem colocada em prática foi, em primeira instância, dessencializar uma identidade que se apresenta como inevitável. Politicamente, a proposta tem pretensões libertárias, na medida em que visa à construção de sujeitos conscientes e autores de si, críticos a determinismos discursivos, os quais se elaboram como históricos e geográficos. A História e a Geografia, compreendidas como as ciências que estudam o tempo e o espaço humanos, aliás, revelam -se instrumentos fecundos para a desconstrução dos estereótipos (e preconceitos) criados pelo atual modelo hegemônico de identidade local e a ideia de região com ele fabricada: suas abordagens e perspectivas (analíticas e não normativas), suas metodologias de investigação (o trato de fontes discursivas e imagéticas, a análise de dados quantitativos e qualitativos, a leitura de documentação histórica), bem como os saberes por ela produzidos contemporaneamente (novos conteúdos-aprendizagens) historicizam e iluminam relações de poder que não estão dadas nas superfícies dos discursos oficiais, folcloristas, memorialistas e mesmo nas formas mais tradicionais de conhecimento histórico, geográfico, literário etc.

Aí reside aquele potencial de extrapolação da ação a outros contextos escolares de que falávamos inicialmente. Como sabemos, os professores encontram, em cada escola, realidades específicas, que podem levar a desdobramentos diferentes. As atividades anteriormente descritas (representações textuais e imagéticas por parte dos estudantes; leitura e análise de imagens, vídeos, e textos contemporâneos e de época; comparação estrutural de produtos culturais) apresentam-se como estratégias profícuas para dar conta do problema identitário na sala de aula, mas 
evidentemente não se configuram como um programa fechado de estudos. Quanto mais o professor estiver atento à recepção/ construção do trabalho pelos estudantes, mais condições terá de desenvolver atividades práticas e teóricas que propiciem aprendizagens significativas. É, portanto, a abordagem geral do tema, traçada anteriormente, que permite gerar tecnologias didáticas consoantes com os objetivos pretendidos.

Para finalizar, vale olhar mais uma vez para o retorno dos estudantes envolvidos na ação. Quando construíram uma narrativa plural sobre a figura do gaúcho, eles pareciam dar uma resposta bastante complexa à pergunta que ora fizemos: se não tomarmos gaúcho como uma categoria classificatória fechada, com sentido único, ou mesmo unívoco, ainda é possível ser gaúcho. Melhor dizendo, a identificação do termo com o gentílico do estado está socialmente sedimentada (e só processos sociais de larga escala poderiam, mais uma vez, modificá-la), mas o que não pode se consolidar é a restrição de nossa experiência a modelos extremamente redutores. Como modo de ser, o skatista de bermudas é tão legítimo quanto o peão de bombachas. Desconstruir o objeto região com as ferramentas de que dispomos implica, portanto, mais do que uma atitude denunciatória: é a tolerância e o respeito às diferenças culturais que se consegue construir.

\section{Referências}

BUZAI, Gustavo Daniel. Evolución del concepto de región ante la emergencia del ciberespacio. Elementos para un debate. Disponível em: $<$ http://www.eListas.net/lista/humboldt $>$. Acesso em: 24 jun. 2004.

GOMES, Carla Renata Antunes de Souza. De rio-grandense a gaúcho: o triunfo do avesso - um processo de representação regional na literatura do século XIX (1847-1877). Porto Alegre: Editoras Associadas, 2009. 352 p. GRIGG, David. Regiões, modelos e classes. In: CHORLEY, Richard; HAGGATT, Peter (Orgs.). Modelos integrados em geografia. Rio de 
Janeiro: Livros técnicos e científicos Editora S.A., Editora da Universidade de São Paulo, 1974. p. 23-66.

GUAZZELI, César Augusto Barcellos. Matrero, guerreiro e peão campeiro: aspectos da construção literária do gaúcho. In: MARTINS, Maria Helena (Org.). Fronteiras culturais: Brasil-Uruguai-Argentina. Porto Alegre: Ateliê Editorial, 2002. p. 107-125.

HAESBAERT, Rogério. RS: latifúndio e identidade regional. Porto Alegre: Mercado Aberto, 1988.

. Regional-global: dilemas da região na geografia contemporânea. Rio de Janeiro: Bertrand Brasil, 2010. 208p.

HOBSBAWM, Eric. Introdução: a invenção das tradições. In.: HOBSBAWM, Eric; RANGER, Terence (Orgs.). A invenção das tradições. 3. ed. São Paulo: Paz e Terra, 2002. p. 9-23.

LENCIONI, Sandra. Região e geografia. São Paulo: Editora da Universidade de São Paulo, 1999. 214p.

MACIEL, Maria Eunice. Tradição e tradicionalismo no Rio Grande do Sul. Humanas, v. 22, n. 1/2, 2000. p. 127-144.

MARTINS, Cyro. Visão crítica do regionalismo. In.: . Sem rumo. 4 ed. Porto Alegre: Movimento, 1979.

MARTINS, Marcos Lobato. História regional. In: PINSKY, Carla Bassanezi (Org.). Novos temas nas aulas de história. 2. ed. São Paulo: Contexto, 2010. p. 135-152.

MEYER, Augusto. Gaúcho: história de uma palavra. Porto Alegre: Instituto Estadual do Livro, 1957. 71p.

NEDEL, Letícia Borges. Um passado novo para uma história em crise: regionalismo e folcloristas no Rio Grande do Sul. Brasília, 2005. Tese (doutorado em História). Instituto de Ciências Humanas, Programa de Pós-Graduação em História, Universidade de Brasília. 560p.

OLIVEIRA, Lúcia Lippi de. Sinais de modernidade na Era Vargas: vida literária, cinema e rádio. In: FERREIRA, Jorge; DELGADO, Lucilia de Almeida (Orgs.). O Brasil republicano: O tempo do nacional-estatismo: do início da década de 1930 ao apogeu do Estado Novo. Rio de Janeiro: Civilização Brasileira, 2003. p. 325-349. 
OLIVEN, Ruben George. A parte e o todo: a diversidade cultural no Brasil-Nação. Petrópolis: Vozes, 1992. 143p.

. A parte e o todo: a diversidade cultural no Brasil-Nação. 2. ed. Petrópolis: Vozes, 2006. 228p.

RAMA, Ángel. Religiões, culturas e literaturas. In: AGUIAR, Flávio; VASCONCELOS, Sandra. Literatura e cultura na américa latina. São Paulo: EDUSP, 2001. p. 281-336.

REVEL, Jacques; CERTEAU, Michel de; JULIA, Dominique. A beleza do morto: o conceito de "cultura popular". In: REVEL, Jacques. A invenção da sociedade. Lisboa: Difel, 1989, p. 49-75.

SUERTEGARAY, Dirce Maria Antunes. Notas sobre epistemologia da geografia. Cadernos Geográficos, Florianópolis, n. 12, 63p., maio 2005.

VELLOSO, Monica Pimenta. Os intelectuais e a política cultural no Estado Novo. In: OLIVEIRA, Lúcia Lippi de. Sinais de modernidade na Era Vargas: vida literária, cinema e rádio. In: FERREIRA, Jorge; DELGADO, Lucilia de Almeida (Orgs.). O Brasil republicano: O tempo do nacional-estatismo: do início da década de 1930 ao apogeu do Estado Novo. Rio de Janeiro: Civilização Brasileira, 2003.

ZALLA, Jocelito. O centauro e a pena: Luiz Carlos Barbosa Lessa (19292002) e a invenção das tradições gaúchas. Porto Alegre, 2010. Dissertação (Mestrado em História). Instituto de Filosofia e Ciências Humanas, Programa de Pós-Graduação em História, Universidade Federal do Rio Grande do Sul, 320 p. 